\title{
Implementing A Cubeacon for Student Presence in Classroom
}

\author{
Yesnida Apriliantari, Sh inta Oktaviana \\ Departement Computer and Informat ic Engeneering \\ Politeknik Negeri Jakarta, Indonesia \\ yesnida.apriliantari.tik14@mhsw.pnj.ac.id, shinta.oktaviana@tik.pnj.ac.id
}

Accepted : May 6 2019. Approved : May 11 2019. Published : May 2019

\begin{abstract}
Student presence is an one of the important thing in academic activity especially in a university. Cubeacon is a bluetooth technology that can be implement for student presence purpose. It is low cost energy and easy to deploy. Cubeacon are used to record the position and the time of student presence. Student can monitoring their presence so students can keep their presence on the track. System are made in two platform, i.e. mobile android and website. API are made to connect each device. Firebase Cloud Messaging are use to send message from website to android device that are use for send notification. Website are built using Laravel as framework. PostgreSQL are use as database. Testing are done to see how the cubeacon can detect the device. The result are that smartphone can detect the cubeacon till $50 \mathrm{~m}$ distance when the re is no barrier, can detect cubeacon till $20 \mathrm{~m}$ distance when the barriers materials are board, and can only detect cubeacon under $10 \mathrm{~m}$ distance when the barrier that is used is wall materials
\end{abstract}

Keywords: IoT (Internet of Things), Cubeacon

\section{INTRODUCTION}

In manual presence system, student presence record is one of the most important issues in an academic environment. Staff or admin have to keep the students record accurately by follow the proper mechanis $m$ to maintain it. By using manual system, staff or admin may have difficulty in managing student's records which are numerous. Moreover, manual system also requires more time for recording and calculating the student's presences. [1]

Manual system is prone to easily get misplaced which can cause miscalculation for student presence.

A Survey is done to see the perspective of students upon the manual system using questioner in one of the department in a university in Indonesia. The result show that $88.2 \%$ students stated that the record of their presence is not accordance with the reality and $97 \%$ students stated that they need presence system that is more transparent and realtime so that they can monitoring their presence record and keep the presence on track. The comparison of student's presence calculation is done to see how the output of the manual system is giving different result that the system should give. The result shows that the manual system gives different result to the calculation that the system should give.

Internet of Things (IoT) is the new concept where the device can communicate each other. The concept is that the device or the physical object exchange data and information to communicate with each other and do some work that has assigned.[2]. The implementation IoT using beacon is one of a kind solution that can be applied to solve the problem of student presence. Using beacon, it will save more time and energy. By implementing IoT, we let the device do the work more than the staff or admin have to do.

\section{CUBEACON}

Cubeacon is a combination between software as-a-service (SaaS) and a hard ware component based on Apple's iBeacon technology. Cubeacon use a BLE (Bluetooth Low Energy) sensor that introduced by Apple named iBeacon. iBeacon are made to be placed indoors. iBeacon sensors can detect device position within the place precisely and send information to the device [3]. BLE technology is very low cost, low power consumption, easy to deploy, and relatively long range. [4].

This system use cubeacon to detect student position to record the presence of students. Figure 2.1 show the system architecture of this application. The students and lectures first have to turn on bluetooth to be detected by cubeacon card and login to the android application. Student can see the details information about their presence information and lecturers can see the student's presence information trough mobile application (android) or website. API (Application Programming Language) is a software intermediary that allows two or more device to communicate each other. After student do the presence, cubeacon will detect the device position and record the student presence and send back the data to the android application. The data are being stored to the database (postgreSQL). Laravel is used to process data from laravel that will be show in website. 


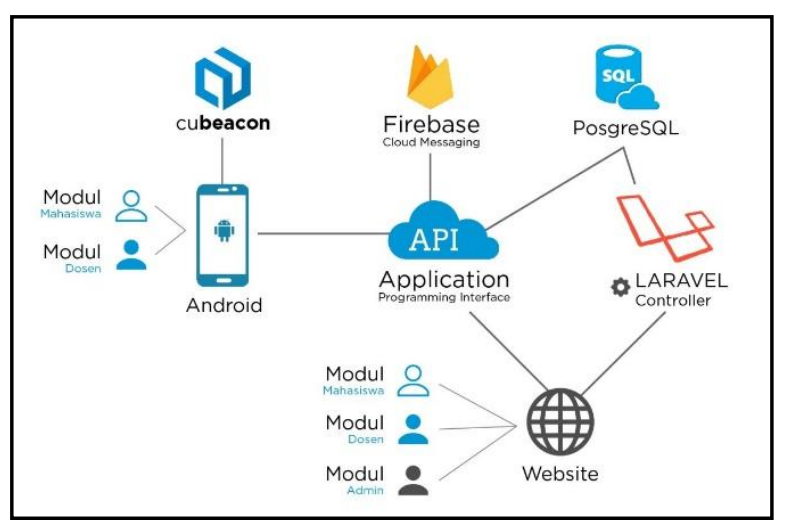

Figure 1 System Architectrure

\section{ReSUlT}

Android application are used to record students attendance. Student can also see their record the cost they have to pay for the compensation. The result of implementation is shown on Figure 1. Students can record their attendance by choose connect absen to begin record the attendance. System then will show the calculation result of their attendance. System will show the total number of attendance, total number of late and the total number of compensation (cost to pay for compensation).

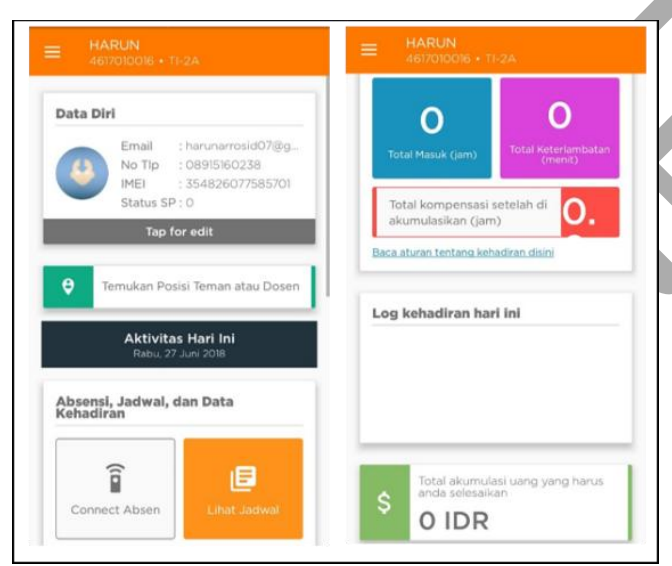

Figure 2 Android Application

This system can show the attendance record real time. Student did not have to wait until the staff done the reporting. Student can check their attendance record anytime and anywhere so that student can monitoring their attendance and keep their attendance on track. This system is made to reduce the human error that may happen when staffs do the reporting from manual to the system.

Web based application is also built for student and lecture to monitoring student presence record trough website and see the record in statistic view. Web based application are also built for admin to manage and monitoring the students presence that is shown in Figure 2 below.

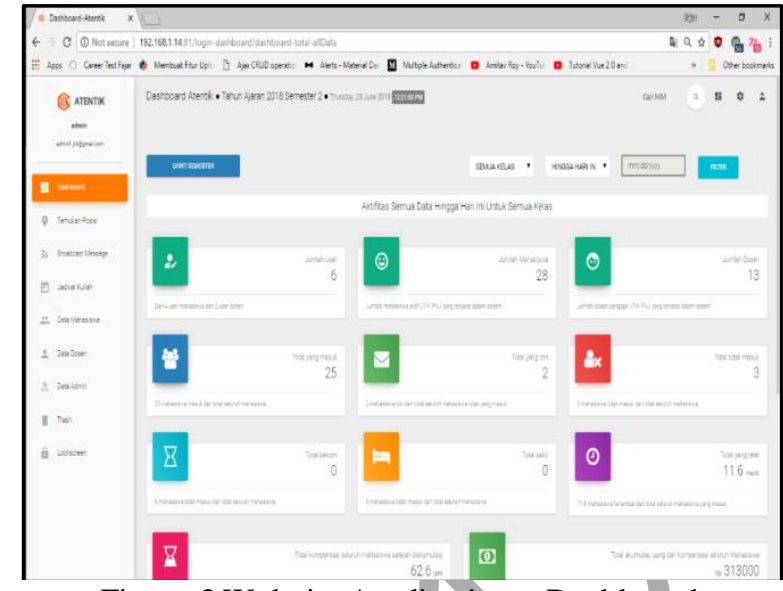

Figure 3 Website Application - Dashboard

Dashboard page let admin to monitoring the students presence record. Admin can also manage data such as broadcast message, schedule, student's data, lecture's data, admin's data and trash's data. Admin can set the rule related presence as shown on the figure below. Admin can set rule for the presence calculation such as set fine cost, total compensation for SP, total minute for every subject, etc.

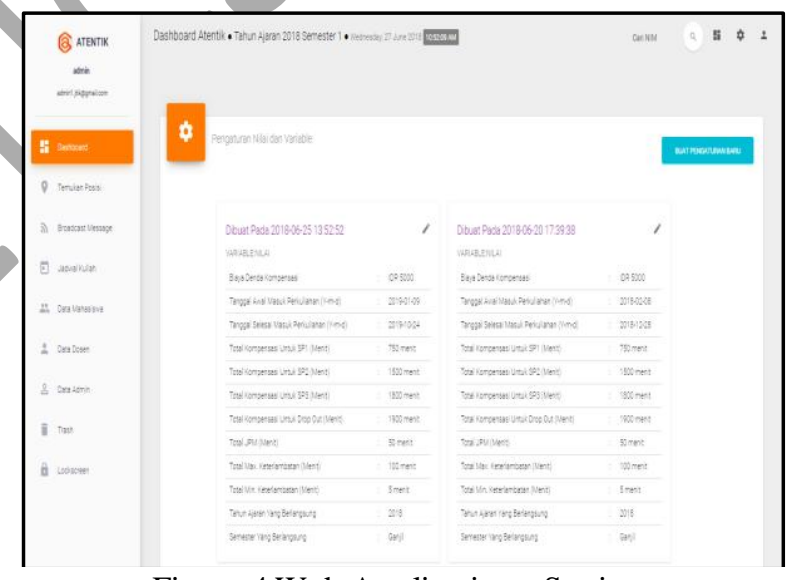

Figure 4 Web Application - Setting

Cubeacon testing is done to see how the cubeacon can detect the device. The testing is done by using different barrier and different distance.

TABLE 1 Cubeacon Testing

\begin{tabular}{cccc}
\hline & \multicolumn{3}{c}{ Testing } \\
\cline { 2 - 4 } Distance & No barrier & $\begin{array}{c}\text { With barrier } \\
\text { Permanent } \\
\text { Material }\end{array}$ & $\begin{array}{c}\text { Non } \\
\text { permanent } \\
\text { material }\end{array}$ \\
\hline 10 & $\sqrt{ }$ & $\mathrm{X}$ & $\sqrt{ }$ \\
\hline 20 & $\sqrt{ }$ & $\mathrm{X}$ & $\sqrt{ }$ \\
\hline 30 & $\sqrt{ }$ & $\mathrm{X}$ & $\sqrt{ }$ \\
\hline 40 & $\sqrt{ }$ & $\mathrm{X}$ & $\mathrm{X}$ \\
\hline 50 & $\sqrt{ }$ & $\mathrm{X}$ & $\mathrm{X}$ \\
\hline 60 & $\mathrm{X}$ & &
\end{tabular}


TABLE 1 shows the result of cubeacon testing. $\sqrt{ }$ symbol shows that the smartphone can detect the cubeacon and $\mathrm{X}$ symbol shows that the smartphone cannot detect the cubeacon. The results show that smartphone can detect the cubeacon until $50 \mathrm{~m}$ distance when there is no barrier, can detect cuebacon until $20 \mathrm{~m}$ distance when the barriers materials are permanent, and can only detect cubeacon under $10 \mathrm{~m}$ distance when the barrier that was used are non permanent materials.

\section{CONClus ION \& SugGeStion}

Implementig cubeacon for student presence can minimize work that should done so it is save time. The system can record the student presence and do calculation accurately so students can monitore their presence record anytime and anywhere. From the cubeacon testing, it is show that cubeacon can detect the smartphone in any various way with regarding to the treatment of testing. It is recommended that the cubeacon are apply in the corner of the room and use permanent material so that device wont detect more than one cubeacon at the time

\section{REFERENCES}

[1] Lukas, S., A. R. Mitra, R. I. Desanti, and D. Krisnadi. 2016. Student Attendance System in Classroom Using Face Recognition Technique. ICTC.

[2] Varshini and Indhurekha. 2017. Attendance System Using Beacon Technology. Intemational Journal of Scientific \& Engineering Research Volume 8.

[3]Freischald, N. 2015. CubeacoN Wants To Be Indonesia's Pioneer In Ibeacon Technology. www.techinasia.com. 30 July 2018. 10.50 AM.

[4] Varela, P.M. and T. Otsuki. 2016. Discovering Co-Located Walking Groups of People Using iBeacon Technology. IEEE Access 4 . 